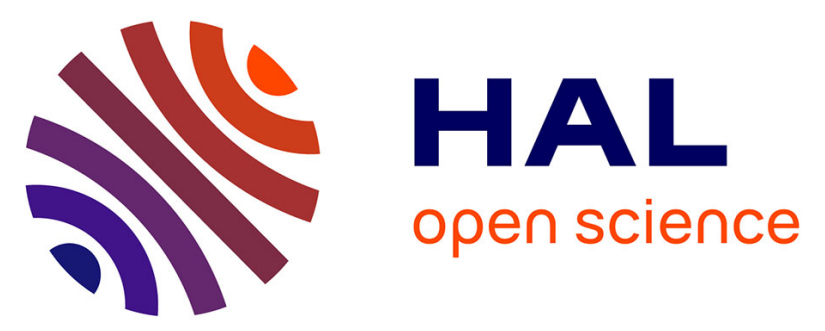

\title{
Surface and morphological investigation of the electrode/electrolyte properties in an all-solid-state battery using a Li2S-P2S5 solid electrolyte
}

\author{
Xiaohan Wu, Mario El Kazzi, Claire Villevieille
}

\section{- To cite this version:}

Xiaohan Wu, Mario El Kazzi, Claire Villevieille. Surface and morphological investigation of the electrode/electrolyte properties in an all-solid-state battery using a Li2S-P2S5 solid electrolyte. Journal of Electroceramics, 2017, 38 (2-4), pp.207-214. 10.1007/s10832-017-0084-z . hal-02781612

\section{HAL Id: hal-02781612 \\ https://hal.science/hal-02781612}

Submitted on 4 Jun 2020

HAL is a multi-disciplinary open access archive for the deposit and dissemination of scientific research documents, whether they are published or not. The documents may come from teaching and research institutions in France or abroad, or from public or private research centers.
L'archive ouverte pluridisciplinaire HAL, est destinée au dépôt et à la diffusion de documents scientifiques de niveau recherche, publiés ou non, émanant des établissements d'enseignement et de recherche français ou étrangers, des laboratoires publics ou privés. 


\section{Surface and morphological investiga- 2 tion of the electrode/electrolyte prop- 3 erties in an all-solid-state battery using ${ }_{4} \mathrm{a} \mathrm{Li}_{2} \mathrm{~S}-\mathrm{P}_{2} \mathrm{~S}_{5}$ solid electrolyte}

Xiaohan $\mathrm{Wu}^{1}$, Mario El Kazzi ${ }^{1}$, and Claire Villevieille ${ }^{*}$

Corresponding author

Dr. Claire Villevieille claire.villevieille@psi.ch, +41 563102410

\section{Abstract}

All-solid-state lithium-ion batteries represent a promising battery technology thanks to the replacement of the volatile and flammable state-of-the-art liquid electrolyte by a solid electrolyte. Despite the recent progress in the synthesis of sulfide based solid electrolyte with high ionic conductivity, little is known about the interface reactivity of the solid electrolyte with electrode materials. In this study, we synthesized and characterized an amorphous solid electrolyte with the nominal composition $\left(\mathrm{Li}_{2} \mathrm{~S}\right)_{3}\left(\mathrm{P}_{2} \mathrm{~S}_{5}\right)$. We assessed the feasibility of using this electrolyte at the laboratory scale, and we discuss the potential challenges that govern its electrochemical performance. Galvanostatic cycling and rate performance measurements were conducted using lithium titanium oxide $\left(\mathrm{Li}_{4} \mathrm{Ti}_{5} \mathrm{O}_{12}\right)$ as the negative electrode material. The electrochemical measurements were performed using two different counter electrodes, namely Li metal and an InLix alloy. The alloy counter electrode suppressed the formation of lithium dendrites, resulting in increased cycling stability and cell safety. Post mortem X-ray photoemission spectroscopy measurements reveal the reactivity of the solid electrolyte $\mathrm{Li}_{3} \mathrm{PS}_{4}$ with the $\mathrm{Li}_{4} \mathrm{Ti}_{5} \mathrm{O}_{12}$, lithium metal, and $\mathrm{InLi} \times$ alloy.

Keywords 


\section{Introduction}

2 High energy and power densities, environment-friendliness, and safety during user operation are just a few of the many criteria required for the next generation of electrochemical energy storage devices. Lithium-ion batteries offer superior specific energy densities compared to other battery chemistries. However, their cost and, more importantly, safety problems raise concerns regarding the use of lithium-ion batteries for mid- to large-scale applications, such as for electric vehicles. All-solid-state lithium-ion batteries (SLiB) are an attractive alternative because the volatile, flammable liquid electrolyte is replaced by a safer solid electrolyte.[1] Historically, the application of SLiBs has been limited, mainly because of the slow ion transport through the solid electrolyte and the resultant low power density of the battery. Recently, sulfide-based superionic conductors (e.g., $\mathrm{Li}_{10} \mathrm{Ge}_{2} \mathrm{PS}_{12}$ (LGPS) and $\left.\mathrm{Li}_{9.54} \mathrm{Si}_{1.74} \mathrm{P}_{1.44} \mathrm{~S}_{11.7} \mathrm{Cl}_{0.3}\right)$ that have conductivities close to those of organic electrolytes have been discovered. $[2,3]$ In addition, solid electrolytes are considered single-ion conductors with lithium ion transference number close to unity.[4] Thus, no polarization due to concentration gradients is expected to occur in SLiBs. Given these properties, the power density of SLiB is no longer limited by the bulk solid electrolyte material. The electrolyte stability is another critical parameter necessary to ensure the long-term operation of the SLiB. Theoretically, sulfide-based electrolytes have a very narrow electrochemical stability window $\left(1.71-2.31 \mathrm{~V} \mathrm{vs.} \mathrm{Li}^{+} / \mathrm{Li}_{\text {for }} \mathrm{Li}_{3} \mathrm{PS}_{4}\right)[5]$. The interface stability of sulfide-based solid electrolytes with typical cathode materials, e.g. lithium cobalt oxide, has been the subject of several experimental studies using transmission electron microscopy (TEM) and electrochemical impedance spectroscopy (EIS), $[6,7]$ and the interface of the electrolyte with metallic lithium has been studied using scanning electron microscopy. $[8,9]$ Very recently, Janek et al. utilized X-ray photoemission spectroscopy (XPS) to further investigate the interface of the solid electrolyte with metallic lithium. $[10,11]$ This method provided a direct way to obtain chemical information about the interface. Wang et al. also used XPS to assess the decomposition mechanism of LGPS at high and low potentials.[12] XPS investigations of the interface between the solid electrolyte and active materials other than metallic lithium have not been reported so far. In this paper, we discuss our attempts to elucidate the interfacial reactivity between the amorphous solid electrolyte $\mathrm{Li}_{3} \mathrm{PS}_{4}$ and a $\mathrm{Li}_{4} \mathrm{Ti}_{5} \mathrm{O}_{12}$ electrode using $X P S$. The impact of the counter electrode on the formation of lithium dendrites was investigated using electrochemical techniques. Prior to the interfacial characterization, electrochemical characterization and cycling of the solid electrolyte using the $\mathrm{Li}_{4} \mathrm{Ti}_{5} \mathrm{O}_{12}$ electrode were carried out to demonstrate the impact of the counter electrode on the cycling stability.

\section{Experimental}

Material preparation

Synthesis of amorphous $\mathrm{Li}_{3} \mathrm{PS}_{4}$ and pellet preparation

The sulfide electrolyte $\mathrm{Li}_{2} \mathrm{~S}-\mathrm{P}_{2} \mathrm{~S}_{5}$ with a molar ratio of 75:25 (referred as $\mathrm{Li}_{3} \mathrm{PS}_{4}$ ) was prepared by ball milling using the synthetic parameters reported in the literature.[4, 13, 14] All procedures were conducted inside an Ar-filled glove box unless stated otherwise. $\mathrm{Li}_{2} \mathrm{~S}$ (Alfa Aesar, purity 99.9\%) and $\mathrm{P}_{2} \mathrm{~S}_{5}$ (Sigma-Aldrich, purity $99 \%$ ) were briefly mixed by hand in an agate mortar and then placed in a zirconia ball milling jar with $5-\mathrm{mm} \mathrm{ZrO}_{2}$ balls. Mechanical milling was conducted for 180 cycles with each cycle consisting of $10 \mathrm{~min}$ active milling $(510 \mathrm{rpm})$ and $5 \mathrm{~min}$ rest. The synthesized powder was ground in an agate mortar and stored in an Ar-filled glove box until further use. 
Dense pellets of $\mathrm{Li}_{3} \mathrm{PS}_{4}$ were prepared by sintering an appropriate amount of the synthesized amorphous powder at ambient temperature and $450 \mathrm{MPa}$ using a Specac GS03000 pressing die and a hydraulic press ( $13 \mathrm{~mm}$ in diameter and $\sim 500 \mu \mathrm{m}$ in thickness).

Preparation of the $\mathrm{LTO}_{\mathrm{L}} \mathrm{Li}_{3} \mathrm{PS}_{4}$ composite electrode (hereinafter referred as the LTO-composite) and cell assembly

$\mathrm{Li}_{4} \mathrm{Ti}_{5} \mathrm{O}_{12}$ (50 wt\%, LTO, Süd-Chemie) and $\mathrm{Li}_{3} \mathrm{PS}_{4}(50 \mathrm{wt} \%)$ were mixed by hand in an agate mortar to produce the composite electrode powder. The InLix alloy was prepared by embedding $\sim 0.38 \mathrm{mg}$ of lithium foil (Alfa Aesar, purity 99.99\%, thickness $200 \mu \mathrm{m}$ ) in a pocket made of $21.5 \mathrm{mg}$ indium foil (Alfa Aesar, purity $99.99 \%$, thickness $100 \mu \mathrm{m})$. Depending on the experiments, the lithium foil was also used as counter electrode and cut into disks of $5 \mathrm{~mm}$ in diameter.

The electrochemical test cell was prepared using a high-pressure cell configuration. The cell body was made of an electrically insulating polyoxymethylene (POM) cylinder with an inner diameter of $7 \mathrm{~mm}$. First, $\mathrm{Li}_{3} \mathrm{PS}_{4}(30 \mathrm{mg})$ was spread onto the bottom pressing plate, and this was then compressed at $100 \mathrm{MPa}$. Approximately $2 \mathrm{mg}$ of LTO-composite powder was then uniformly spread on one side of the solid electrolyte layer and served as working electrode. This electrolyte-electrode bilayer was compressed at $400 \mathrm{MPa}$ to form a dense pellet and ensure intimate contact between the electrode and electrolyte. Finally, the counter electrode, either Li or InLix alloy, was pressed on the other side of the solid electrolyte. $\mathrm{Cu}$ and Al foils served as current collector on the counter and working electrode side, respectively. The internal pressure of the cell stack was maintained by the screws as shown in Figure 1.

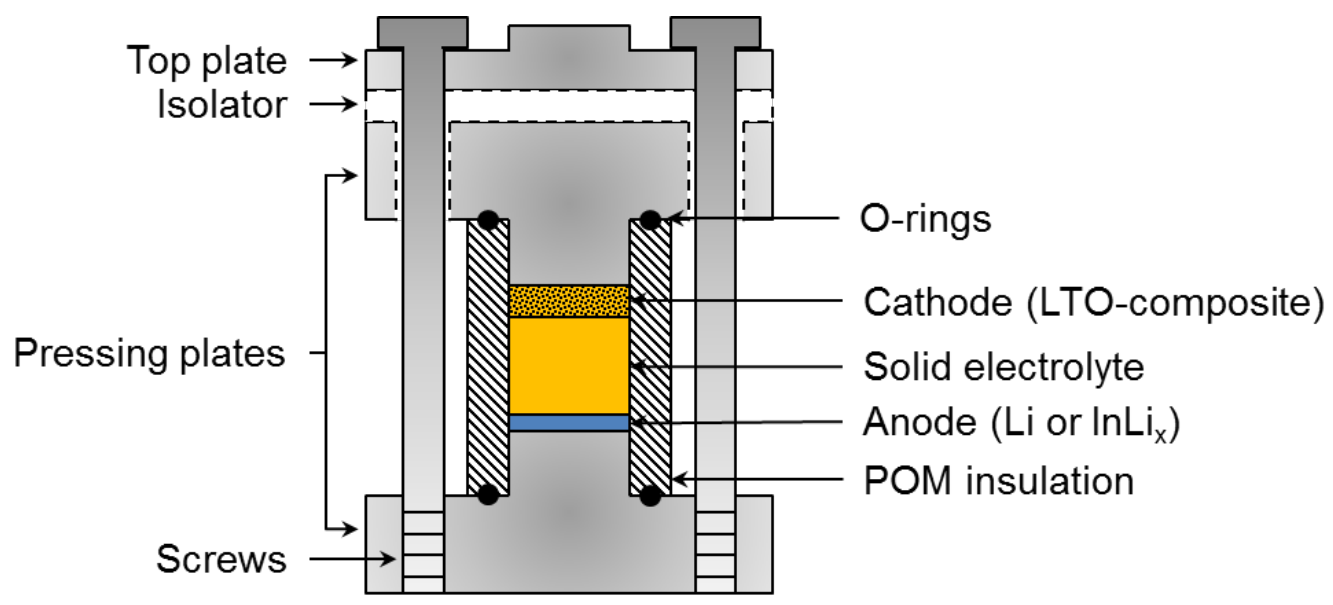

Figure 1. Schematic design (not to scale) of the all-solid-state test cell.

\section{Material characterization}

Powder X-ray diffraction (XRD) experiments were conducted on a PANalytical Empyrean diffractometer using $\mathrm{Cu} \mathrm{K}_{\alpha}$ radiation. The solid electrolyte powder was filled in a $0.7-\mathrm{mm}$ borosilicate glass capillary and sealed under an inert atmosphere. The patterns were collected between $10^{\circ}$ and $60^{\circ}$ in $2 \theta$ with a step of $0.03^{\circ}$. To improve the signal to noise ratio, we collected each pattern 12 times.

Raman spectroscopy measurements were carried out with a Raman microscope (Labram HR800 Horiba-Jobin Yvon, Japan) with a He-Ne laser $(632.8 \mathrm{~nm})$ and a 50x objective (ULWDMS Plan 50, $\mathrm{NA}=0.55$, Olympus, Japan). 
1 Scanning electron microscopy (SEM) measurements were performed with an Ultra55 (Carl Zeiss) using

2 a secondary electron detector (SE2). The SEM samples were fixed on the sample holder by means of

3 an adhesive conductive carbon tape. An airtight transfer chamber was used to avoid any exposure of

4 the sample to air.

5 X-ray photoemission spectroscopy measurements were carried out with a VG ESCALAB 220iXL spectrometer (Thermo Fisher Scientific) using focused monochromatized Al $\mathrm{K}_{\alpha}$ radiation (1486.6 eV). After disassembling the cells in a glove box, the electrodes were transferred to the XPS spectrometer using an argon-filled transfer chamber to avoid air exposure and surface modification. The spectrometer was calibrated using the $\mathrm{Ag} 3 \mathrm{~d}_{5 / 2}$ peak with a binding energy of $368.3 \mathrm{eV}$. The samples had an analyzed area of about $500 \mu \mathrm{m}^{2}$, and the analysis chamber had a recorded pressure of approximately $2 \times 10^{-9} \mathrm{mbar}$. The spectra were recorded in constant analyzer energy mode at a pass energy of $30 \mathrm{eV}$.[15] The acquired spectra on different samples were normalized by the intensities of the respective $\mathrm{S} 2 \mathrm{p}$ core level in $\mathrm{Li}_{3} \mathrm{PS}_{4}$. To compensate for any charging effects on the surface, we aligned all spectra using the $\mathrm{C} 1 \mathrm{~s}$ peak of the hydrocarbon components at $285.7 \mathrm{eV}$. Peak deconvolution was performed by applying the sum of Gaussian (70\%) and Lorentzian (30\%) line shapes after Shirley-type background subtraction. The deconvolution of the $S 2 p_{3 / 2-1 / 2}, P 2 p_{3 / 2-1 / 2}$, and Ti2 $p_{3 / 2-1 / 2}$ peaks were carried out by fixing their spin-orbit splitting $(\Delta E)$ and branching ratio $(\beta)$ to $\left(\Delta E_{S}=1.2 \mathrm{eV}, \beta_{\mathrm{S}}=0.5\right)$, $\left(\Delta E_{\mathrm{P}}=0.87 \mathrm{eV}, \beta_{\mathrm{p}}=0.5\right)$, and $\left(\Delta E_{\mathrm{Ti}}=5.7 \mathrm{eV}, \beta_{\mathrm{Ti}}=0.5\right)$, respectively.

\section{Electrochemical characterization}

AC-Electrochemical impedance spectroscopy (EIS) was conducted on symmetric cells using blocking electrodes and the solid electrolyte $\mathrm{Li}_{3} \mathrm{PS}_{4}$. Approximately $30 \mathrm{mg}$ of the solid electrolyte was pelletized under the same conditions as described previously using carbon-coated aluminum foil as the current collector. The thickness of the electrolyte pellet was measured using a micro-caliper $(\Delta l= \pm 10 \mu \mathrm{m})$. The measurements were conducted at the open circuit potential (OCP) with an AC perturbation of $10 \mathrm{mV}$ in the frequency range of $1 \mathrm{MHz}$ to $1 \mathrm{~Hz}$. The spectra were recorded on a Biologic VMP-3 potentiostat. The temperature was controlled by an ESPEC SU-221 temperature chamber. Prior to each measurement, the cells were allowed to reach a steady state for $12 \mathrm{~h}$. The EIS measurements were conducted between $-20^{\circ} \mathrm{C}$ and $80^{\circ} \mathrm{C}$ in $10^{\circ} \mathrm{C}$ increments with an exception for the measurement at $25^{\circ} \mathrm{C}$. The spectra were fitted using Zview and an equivalent circuit consisting of a series connection of the bulk electrolyte resistance and a constant phase element representing the imperfect capacitive behavior of the interface.

DC-Polarization experiments were conducted using a Biologic VMP-3 potentiostat and the same blocking electrode configuration as in the EIS experiments. After stabilization at $25^{\circ} \mathrm{C}$ for $6 \mathrm{~h}$, a DC voltage of $0.5 \mathrm{~V}$ was applied. The current response was recorded as a function of time. After the current had reached a steady state, the value recorded was used to estimate the electronic conductivity.

Cyclic voltammetry (CV) and cycling experiments were performed at room temperature using Computer Controlled Cell Capture software and hardware (CCCC, Astrol Electronic AG, Switzerland). When using the $\operatorname{lnL} \mathrm{i}_{x}$ alloy $(x<1)$ as the counter electrode, a voltage shift of $620 \mathrm{mV}$ was taken into account for the cycling window.[16] CV measurements were conducted at a scan rate of $50 \mu \mathrm{V} \mathrm{s}{ }^{-1}$. The LTO 
galvanostatic cycling experiments were conducted is denoted as the C-rate $(f)$ with respect to the theoretical charges $\left(Q_{\text {theo }}\right)$ of the respective LTO working electrode. The C-rate was calculated as follows:

$$
f=\frac{i}{Q_{\text {theo }}}
$$

Equation 1

3

4 At a C/10 rate, the cell will be fully discharged (or charged) in $10 \mathrm{~h}$, based on a $100 \%$ theoretical charge of the active material. When cycling successively at different rates, a potentiostatic step was applied at the low and high voltage limit after each galvanostatic step to fully lithiate and delithiate the electrode, respectively. The constant voltage hold was terminated once the current inside the cell fell below $5 \mu \mathrm{A}$.

Galvanostatic lithium plating and stripping experiments were conducted to investigate the reactivity of the solid electrolyte with metallic lithium under electrochemical cycling conditions. The cells were built in a similar manner as that for the cycling experiment described above. The working electrode, in this case, was the stainless steel current collector and the counter electrode was the above mentioned InLi $\mathrm{i}_{\mathrm{x}}$ alloy. First, lithium was deposited on the current collector by applying a current of $-20 \mu \mathrm{A}$ for $10 \mathrm{~h}$. The deposited amount of lithium corresponds to a thickness of $\sim 2.5 \mu \mathrm{m}$ assuming a homogenous deposition of the film. This initially deposited charge equivalent of lithium is further referred to as $Q_{0}$. Subsequently, $10 \%$ of $Q_{0}$ was stripped $\left(Q_{c}\right)$ and plated $\left(Q_{D}\right)$ in each step to simulate the cycling

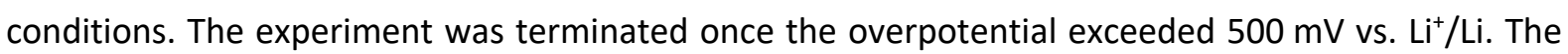
number of cycles before termination $(n)$ was then used to estimate the lithium electrode cyclic efficiency as described by Equation 2.[17]

$$
\eta=\frac{Q_{c} * n}{Q_{D} * n+Q_{0}}
$$

Equation 2

\section{Results and discussion}

\subsection{Material synthesis and characterization}

As can be seen from the XRD results shown in Figure $1 \mathrm{a}, 30 \mathrm{~h}$ of active milling were necessary to obtain an amorphous solid electrolyte. $[4,13,14]$ On lowering the effective milling time to $20 \mathrm{~h}$, we noticed the presence of crystalline $\mathrm{Li}_{2} \mathrm{~S}$, indicating that the synthesis had not reached completion.

To confirm the conversion of the precursor to the desired solid electrolyte compound (after $30 \mathrm{~h}$ ), we conducted Raman spectroscopy measurements, as shown in Figure $1 \mathrm{~b}$. The formation of $\mathrm{PS}_{4}{ }^{3-}$ is indicated by the peak at $421 \mathrm{~cm}^{-1}$, as reported in the literature, $[14,18,19]$ while a weak shoulder at 387 $\mathrm{cm}^{-1}$ corresponds to the formation of $\mathrm{P}_{2} \mathrm{~S}_{6}{ }^{4-}$ dimers. Yamada et al. have suggested that local inhomogeneity during the ball mill synthesis could lead to the formation of this sulfur-deficient phase.[14] 

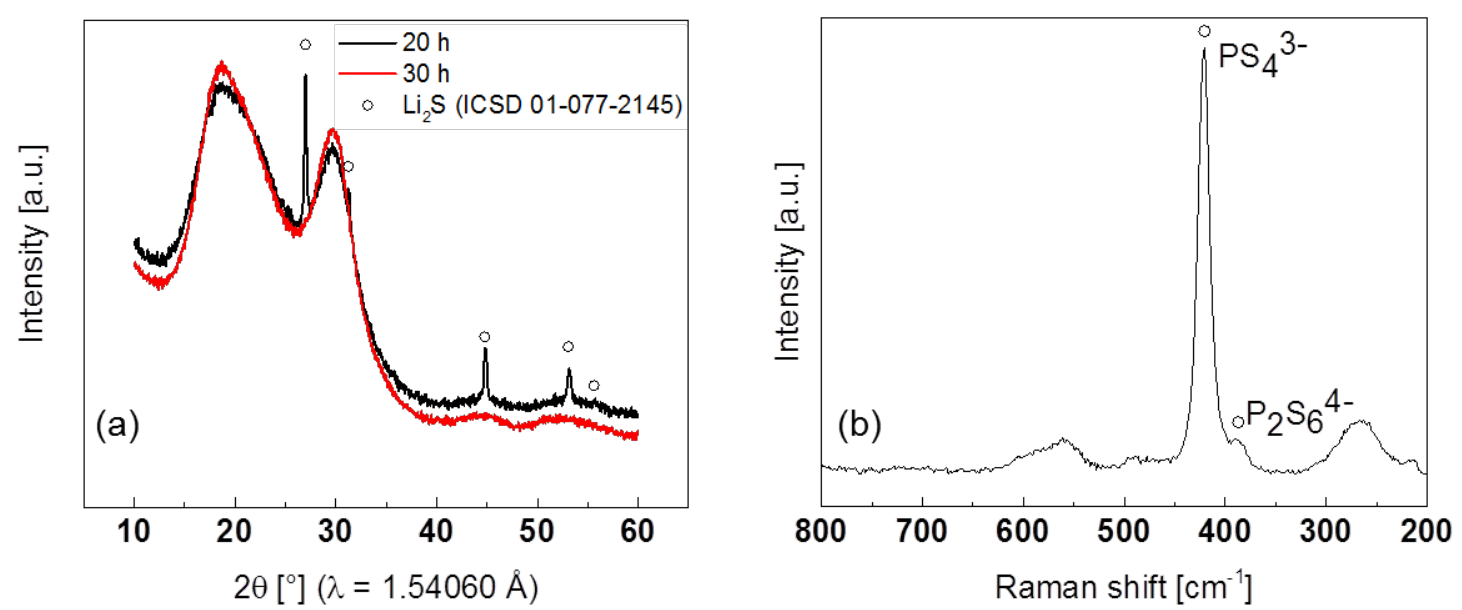

Figure 2. (a) XRD patterns of $\mathrm{Li}_{3} \mathrm{PS}_{4}$ powders milled for 20 and $30 \mathrm{~h}$. (b) Raman spectrum of the $\mathrm{Li}_{3} \mathrm{PS}_{4}$ powder after $3 \mathrm{~h}$ effective ball milling time.

4 In the next step, the solid electrolyte powder was compressed to produce dense pellets prior to the 5 electrochemical measurements. Based on the mass and the measured volume of the pelletized $\mathrm{Li}_{3} \mathrm{PS}_{4}$, 6 its apparent density was estimated to be $1.79 \mathrm{~g} \mathrm{~cm}^{-1}$, reaching approximately $95 \%$ of the theoretical 7 density. The dense morphology of the electrolyte pellet was confirmed by SEM, as illustrated in Figure 8 3. The SEM image further shows imperfection of the process due to the uniaxial pressing. In addition to the large, dense areas, coarse areas with many grain boundaries were observed.
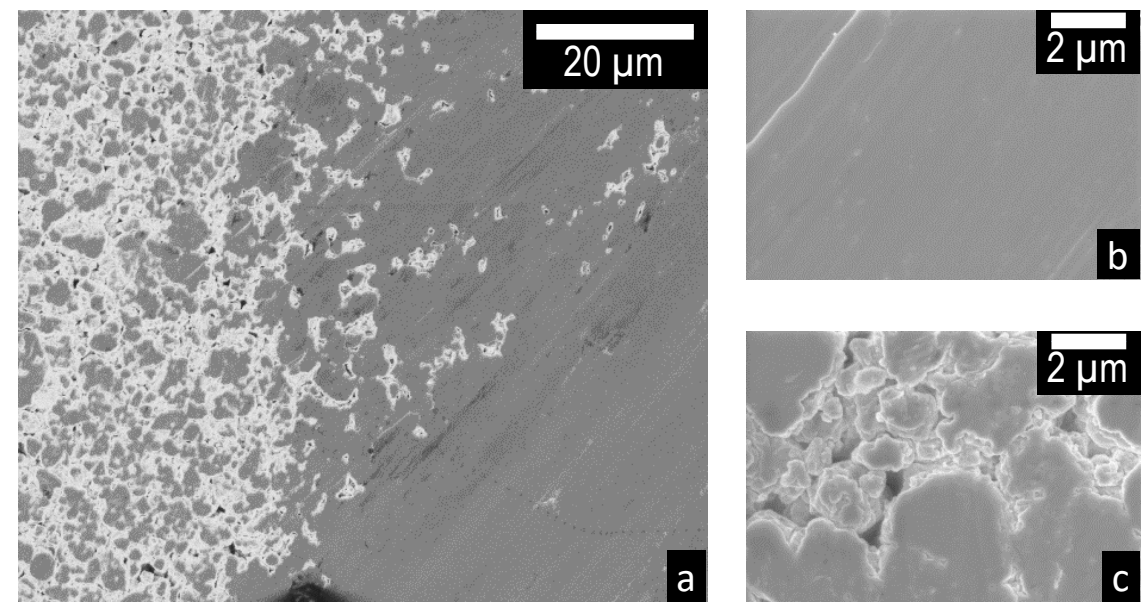

Figure 3. SEM image of the $\mathrm{Li}_{3} \mathrm{PS}_{4}$ pellet compressed at $450 \mathrm{MPa}$ showing a) the dense pellet with inhomogeneous morphology due to uniaxial pressing and b) dense and c) coarse areas at higher magnification.

\subsection{Lithium ion conductivity measurements}

The ionic conductivity of $\mathrm{Li}_{3} \mathrm{PS}_{4}$ was measured by means of AC-EIS measurements, and the activation energy was extracted from the temperature dependent Arrhenius plot as shown in Figure 4 . The room temperature ionic conductivity is around $0.4 \mathrm{mS} \mathrm{cm}^{-1}$, and the activation energy was determined to be $0.37 \mathrm{eV}$. The values found in this study are in good agreement with those reported in the literature.[4] The electric conductivity of this solid electrolyte pellet was determined to be less than $5 \times 10^{-}$ ${ }^{10} \mathrm{~S} \mathrm{~cm}^{-1}$, meaning that the solid electrolyte is an electrical insulator. 


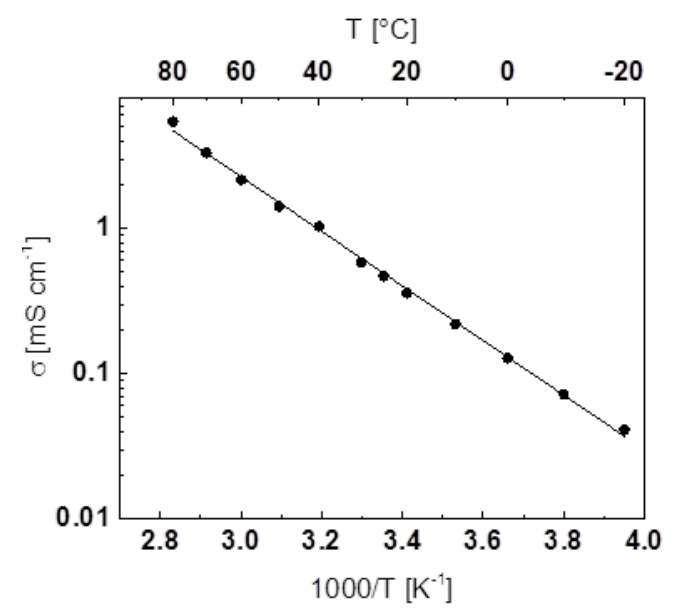

2 Figure 4. Temperature dependence of the ionic conductivity of $\mathrm{Li}_{3} \mathrm{PS}_{4}$ in pellet form. The solid line indicates the linear 3 regression fit of the Arrhenius plot.

\subsection{Cycling behavior with LTO as the working electrode and lithium metal as the} counter electrode

The theoretical potential stability window of $\mathrm{Li}_{3} \mathrm{PS}_{4}$ has been determined to be between 1.71 and $2.31 \mathrm{~V}$ vs. Li ${ }^{+} / \mathrm{Li}$.[5] Thus, most commonly used cathode materials, e.g., lithium iron phosphate (LFP), lithium cobalt oxide (LCO), and lithium nickel cobalt manganese oxide (NCM), would result in the irreversible oxidation of the solid electrolyte. We, thus, decided to study the cycling behavior of the $\mathrm{Li}_{3} \mathrm{PS}_{4}$ solid electrolyte using LTO as the working electrode material and lithium metal as the counter electrode.

In the first attempt to cycle LTO vs. metallic lithium, we observed the irreversible cycling behavior of the test cells. As can be seen in the CV of the $\mathrm{Li}_{\mid} \mathrm{Li}_{3} \mathrm{PS}_{4} \mid \mathrm{LTO}$-composite cell (Figure $5 \mathrm{a}$ ), it was only possible to obtain one lithiation of LTO, with the reduction occurring between $1.5 \mathrm{~V}$ and $1.1 \mathrm{~V} \mathrm{vs} . \mathrm{Li}^{+} / \mathrm{Li}$, and significant peak broadening was observed. Notably, even at $1 \mathrm{~V} \mathrm{vs.} \mathrm{Li}^{+} / \mathrm{Li}$, the lithiation did not complete, as the current did not reach $0 \mathrm{~mA}$, indicating that some current was still flowing inside the cell. The delithiation was partial, with a broad peak at 1.6-1.8 V vs. $\mathrm{Li}^{+} / \mathrm{Li}$. However, once a potential of $1.8 \mathrm{~V}$ vs. $\mathrm{Li}^{+} / \mathrm{Li}$ had been reached, the current suddenly increased to very high values, and the cell stopped (shadowed area). This steep current increase at a given potential indicates a drop in the internal electrical resistance of the cell, generally referred to as an internal short-circuit. Similar behavior was also observed during galvanostatic cycling of a cell with the same $\mathrm{Li}_{\mid}\left|\mathrm{Li}_{3} \mathrm{PS} \mathrm{S}_{4}\right| \mathrm{LTO}$ configuration, as shown in Figure $5 \mathrm{~b}$. The first lithiation occurs with the known potential plateau for LTO at $\sim 1.55 \mathrm{~V}$ vs. $\mathrm{Li}^{+} / \mathrm{Li}$ despite the large polarization, most probably caused by the applied cycling rate. However, once again the delithiation was abruptly terminated by strong fluctuations in the potential, indicative of the internal short-circuit, as reported previously.[8] Even after uniaxial pressing (see Figure 3), some porosity remained, so the contact between the solid electrolyte and the lithium metal anode is likely not homogeneous, and locally high current densities cause dendrite formation by acting as preferential sites for lithium metal deposition. 

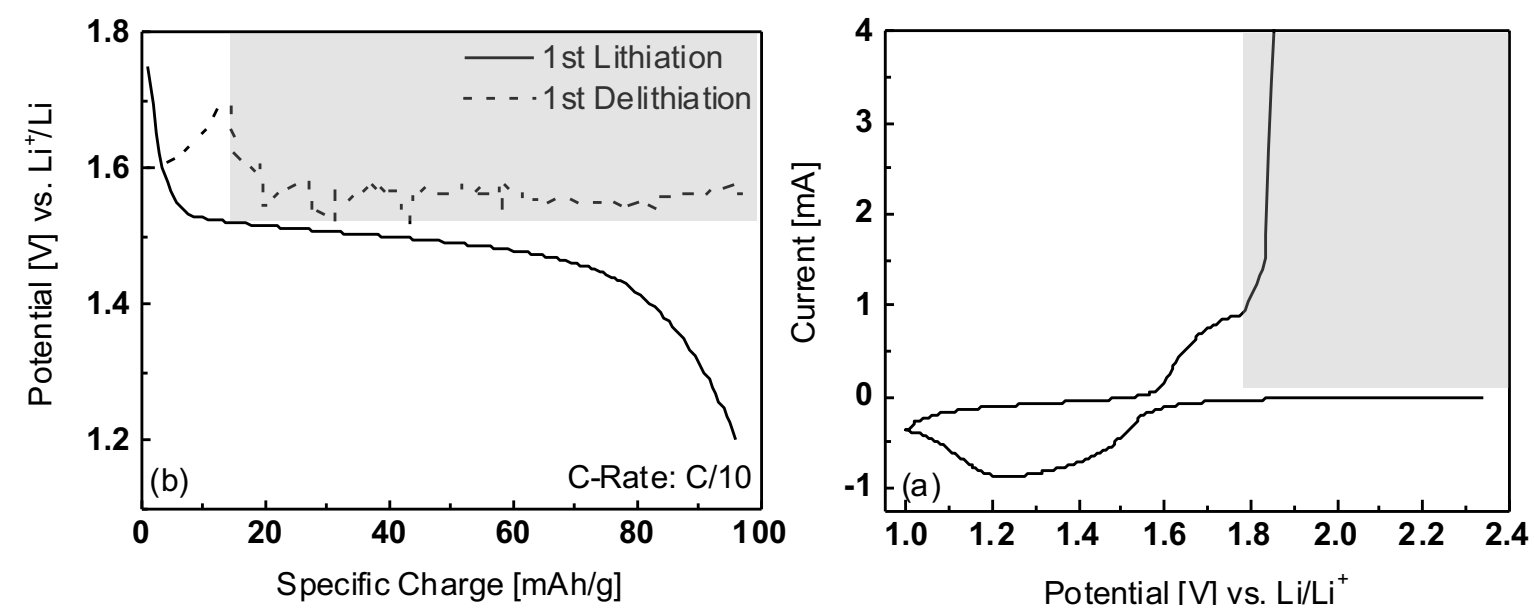

Figure 5. (a) Cyclic voltammetry (Scan rate: $50 \mu \mathrm{V} \mathrm{s}^{-1}$ ) of the Li|Li $\mathrm{PS}_{4} \mid \mathrm{LTO}$-composite cell. (b) Galvanostatic curves at C/10 rate of an all-solid-state half-cell with the $\mathrm{Li}_{3} \mathrm{PS}_{4}$ solid electrolyte, LTO-composite as the working electrode, and $\mathrm{Li}$ as the counter electrode. The shadowed areas represent the short-circuit situation.

The formation of dendrites is further illustrated in Figure 6, which presents the maximum and minimum voltages observed during each lithium stripping and plating step. Internal short-circuits are visible after only three cycles of lithium plating and stripping. Using Equation 2, the cycling efficiency was estimated to be $23 \%$.

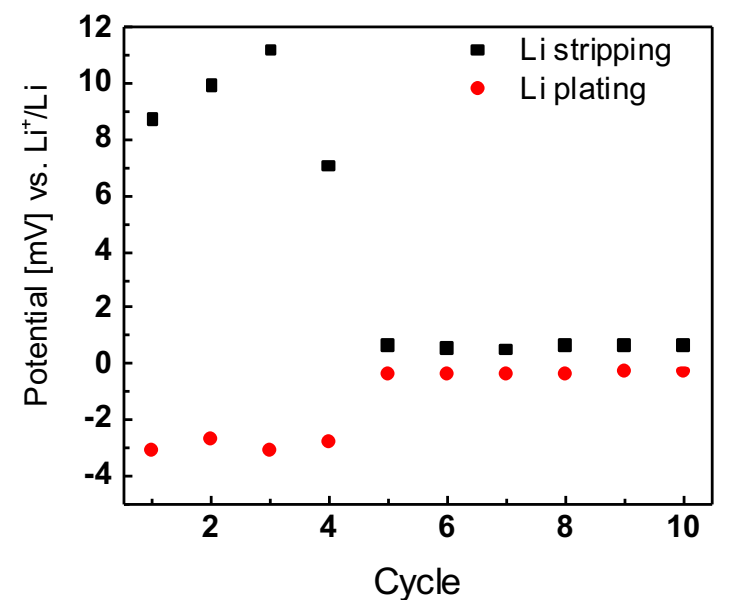

Figure 6. Peak overpotentials during lithium plating and stripping in a $\mathrm{Li}\left|\mathrm{Li}_{3} \mathrm{PS}_{4}\right| \mathrm{SS}$ cell configuration. Initially plated charge equivalents of metallic lithium on the solid-state working electrode $\left(Q_{0}\right): 0.2 \mathrm{mAh} \mathrm{cm}^{-2}$. Charge equivalents passed through each cycle $\left(Q_{c}, Q_{D}\right): 0.02 \mathrm{mAh} \mathrm{cm}^{-2}$.

The chemical composition of the surface of the $\mathrm{Li}_{3} \mathrm{PS}_{4}$ solid electrolyte in contact with metallic lithium was examined by post mortem XPS. As shown in Figure $7 \mathrm{a}$, the pristine sample yielded the main $\mathrm{S} 2 \mathrm{p}_{3 / 2}$ peak at $162.2 \mathrm{eV}$ and that of $\mathrm{P} 2 \mathrm{p}_{3 / 2}$ at $132.8 \mathrm{eV}$, which is in good agreement with the literature values. $[12,20]$ Besides $\mathrm{Li}_{3} \mathrm{PS}_{4}$, the pristine sample contains polysulfides, as suggested by the presence of sulfur-sulfur bonds (peak of $S 2 p_{3 / 2}$ at $163.3 \mathrm{eV}$ ). [21] The post mortem XPS analysis shown in Figure $7 \mathrm{~b}$ was conducted at the interface between the solid electrolyte and metallic lithium, revealing further smaller amounts of reduced sulfur species. A new peak appeared at $160.8 \mathrm{eV}\left(\mathrm{S} 2 \mathrm{p}_{3 / 2}\right)$, and this was attributed to the formation of $\mathrm{Li}_{2} \mathrm{~S}$, in accordance with theoretical calculations and experimental data. $[5,21,22]$ Apart from these observations, no changes in the chemical environment of phosphorus were observed. $\mathrm{Li}_{2} \mathrm{~S}$ is a poor electronic and ionic conductor at ambient temperatures. Therefore, the presence of $\mathrm{Li}_{2} \mathrm{~S}$ likely increases the interfacial resistance. However, this effect alone would not 
explain the short-circuit behavior observed in the cycling experiment. Thus, the growth of lithium dendrites appears to be the sole cause of cell failure.

a)

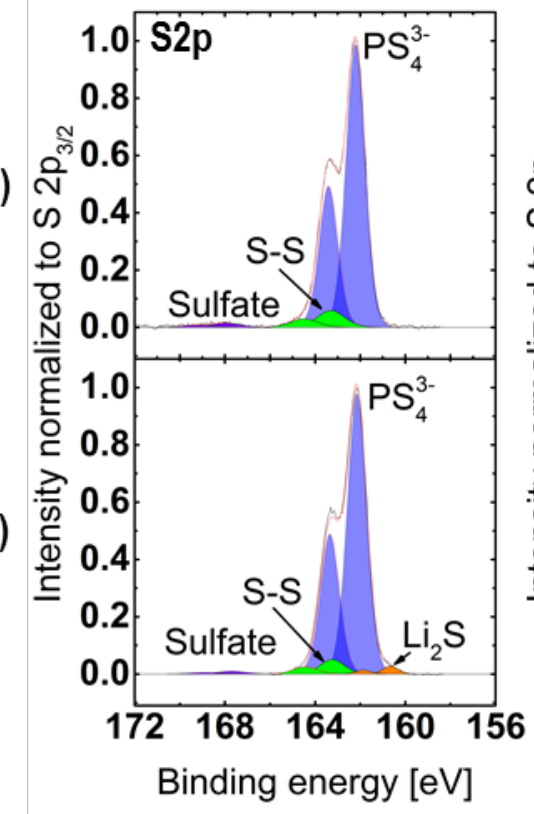

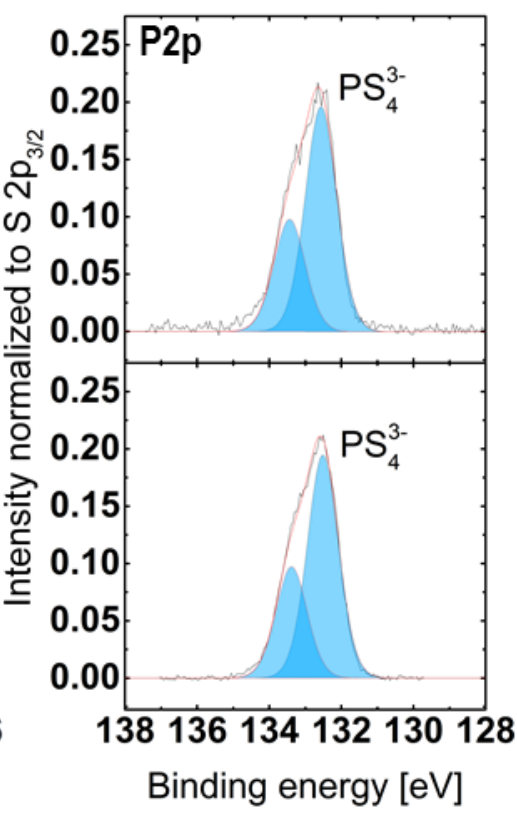

Binding energy $[\mathrm{eV}]$

Figure 7. S2 $p_{3 / 2-1 / 2}$ and $P 2 p_{3 / 2-1 / 2} X P S$ core levels acquired a) on pristine $\mathrm{Li}_{3} P S_{4}$ and $b$ ) at the interface between $\mathrm{Li}_{3} \mathrm{PS}_{4}$ and the Li counter electrode after five cycles.

As demonstrated, metallic lithium is not a suitable counter electrode for use with the $\mathrm{Li}_{3} \mathrm{PS}_{4}$ solid electrolyte. In the literature, $I n L_{x}$ alloys have been reported to be more stable; thus, we discuss these alloys in the next section.

\subsection{Cycling behavior with LTO as the working electrode and an In-Li alloy as the} counter electrode

An advantage of $I n L_{x}$ (with respect to the electrochemical stability of $\mathrm{Li}_{3} \mathrm{PS}_{4}$ ) is its higher potential compared to that of a Li-metal counter electrode $(620 \mathrm{mV} \mathrm{vs.} \mathrm{Li+/Li} \mathrm{for} \mathrm{x}<1)$. [16, 23] As can be seen in the CV plotted in Figure 8a, the InLi $i_{x}$ alloy is the key to the successful cycling of the solid-state In$\mathrm{Li}_{x}\left|\mathrm{Li}_{3} \mathrm{PS}_{4}\right| \mathrm{LTO}$-composite cell batteries. The CV shows the reversible lithiation and delithiation of LTO with reversible lithiation and delithiation peaks centered at $\sim 1.49 \mathrm{~V}$ and $\sim 1.73 \mathrm{~V} \mathrm{vs}$. Li ${ }^{+} / \mathrm{Li}$, respectively. We observed a very large overpotential due to the low ionic conductivity and the relatively high current occurring during the $\mathrm{CV}$ measurements. Similar behavior was observed in the galvanostatic cycles, which are shown in Figure 8b, where different cycling rates were applied. As shown in Figure 8b, as the cycling rate slowed, the polarization was reduced, and the obtained specific charge increased. At $\mathrm{C} / 20$, a specific charge of more than $150 \mathrm{mAh} / \mathrm{g}_{\text {что }}$ was obtained, more than $85 \%$ of the theoretical specific charge of LTO. The missing charges may be a consequence of insufficient electronic conductivity due to the absence of conductive carbon additive in the electrode. Even at $C / 5$, the specific charge retention was over $100 \mathrm{mAh} / \mathrm{g}_{\text {LTO }}$. However, at higher rates, the performance of the cell decreased drastically, falling to a specific charge of less than $50 \mathrm{mAh} / \mathrm{g}$ at $2 \mathrm{C}$. 

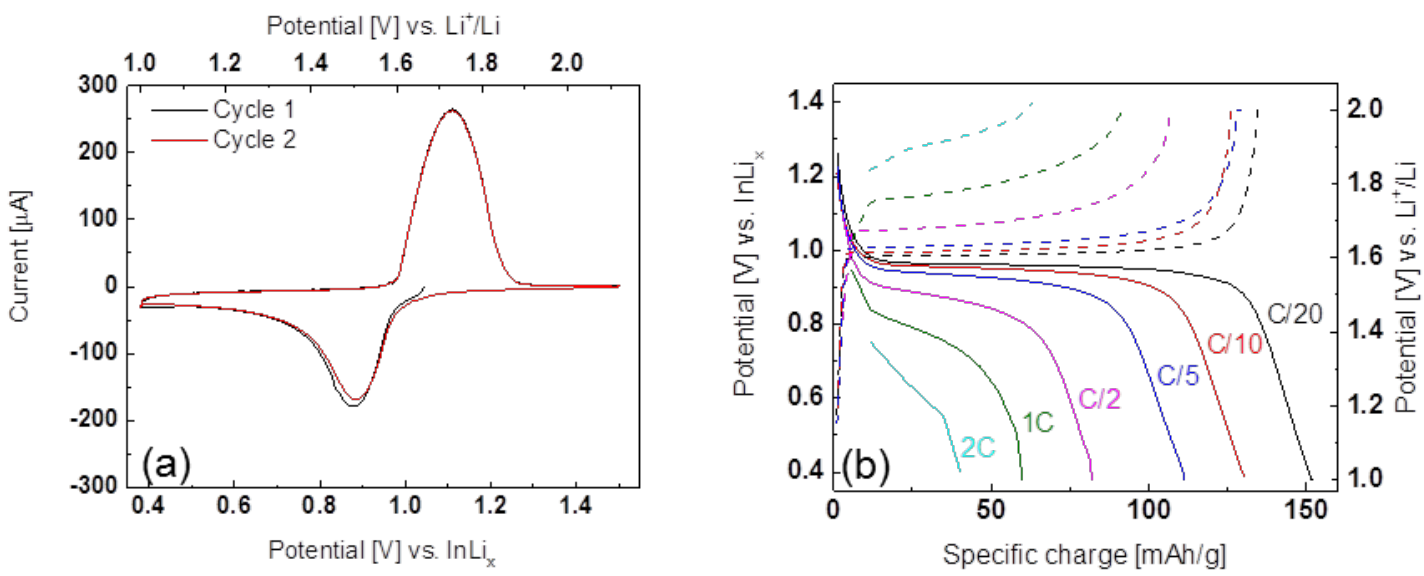

Figure 8. (a) Cyclic voltammetry (scan rate: $50 \mu \mathrm{V} \mathrm{s}^{-1}$ ) of $\operatorname{InLi}_{x}\left|\mathrm{Li}_{3} \mathrm{PS}_{4}\right|$ LTO-composite cell; (b) Voltage profile of the first galvanostatic lithiation and delithiation of the $\operatorname{InLi}_{x}\left|L_{3} \mathrm{PS}_{4}\right|$ LTO-composite cell at different C-rate. A potentiostatic step was introduced after each galvanostatic step.

To determine the capacity retention arising from the lithiation and delithiation, a potentiostatic step (not plotted in Figure 6b) was introduced to either fully charge or discharge the cells. Notably, at rates of $>C / 5$, the specific charge was always higher for the delithiation than for the lithiation. This may arise from the sluggish kinetics of the $\ln \mathrm{Li}_{x}$ counter electrode.

Figure 9a shows the long-term stability of the $\operatorname{InLi} \mathrm{i}_{x}\left|\mathrm{Li}_{3} \mathrm{PS}_{4}\right| \mathrm{LTO}$-composite cell cycled galvanostatically at a $\mathrm{C} / 10$ rate. Overall, with the exception of the first cycle, the coulombic efficiency exceeded $99 \%$ over 70 cycles, indicating the highly reversible (de)lithiation of LTO. The specific charge remained constant at ca. $120 \mathrm{mAh} / \mathrm{g}_{\text {цто }}$ for 70 cycles (lower than the theoretical capacity, most probably due to the slight polarization observed). As shown in Figure $9 b$, there is no additional overpotential build-up during cycling in the voltage profiles, indicating the good cycling stability of the cell and the favorable nature of the electrolyte-electrode interface. The good cyclability observed for LTO electrode can be explained as follow: the pristine LTO has a low electronic conductivity, which increases drastically once the titanium is reduced. The high conductivity is maintained during cycling, due to the fact that some $\mathrm{Ti}^{3+}$ is still present, as shown by the XPS experiments.
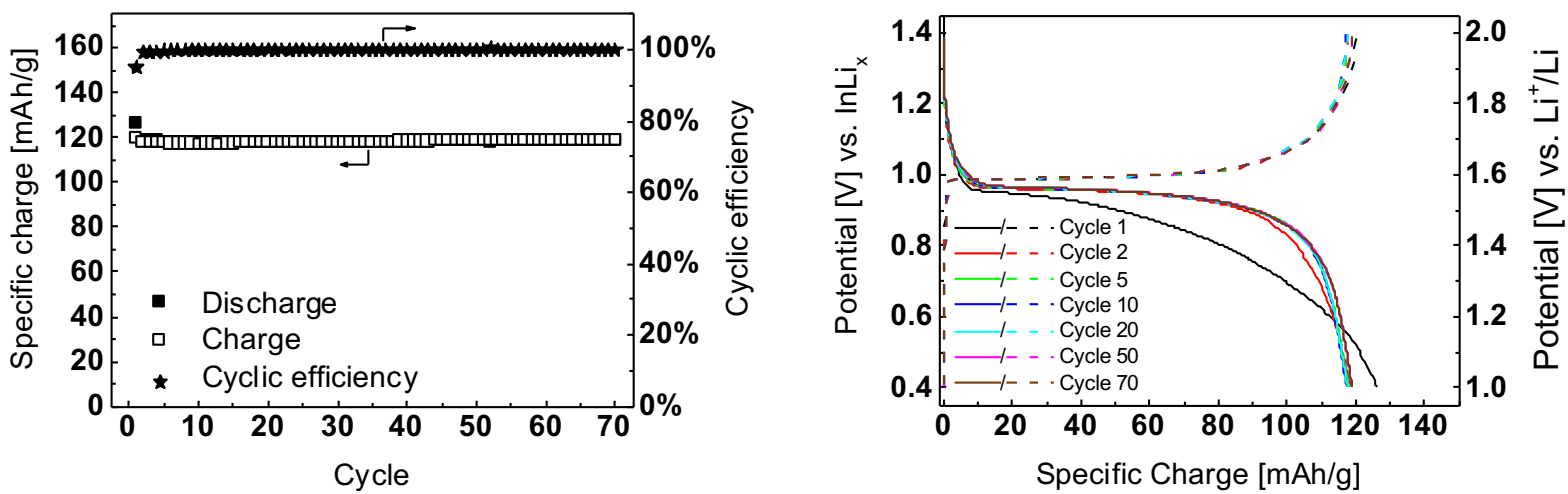

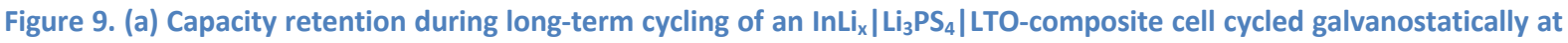
a $\mathrm{C} / 10$ rate. (b) Voltage profiles during cycling.

Post-mortem XPS measurements are useful to probe interfacial reactions because the method is highly surface sensitive. During the first lithiation, as depicted in Figure 10b, we observed the reduction of $\mathrm{Ti}^{4+}$ to $\mathrm{Ti}^{3+}$. However, the reduction of LTO is not $100 \%$ reversible upon delithiation because traces of $\mathrm{Ti}^{3+}$ were detected, as shown in Figure 10c. In addition to the LTO activity, no electrolyte 

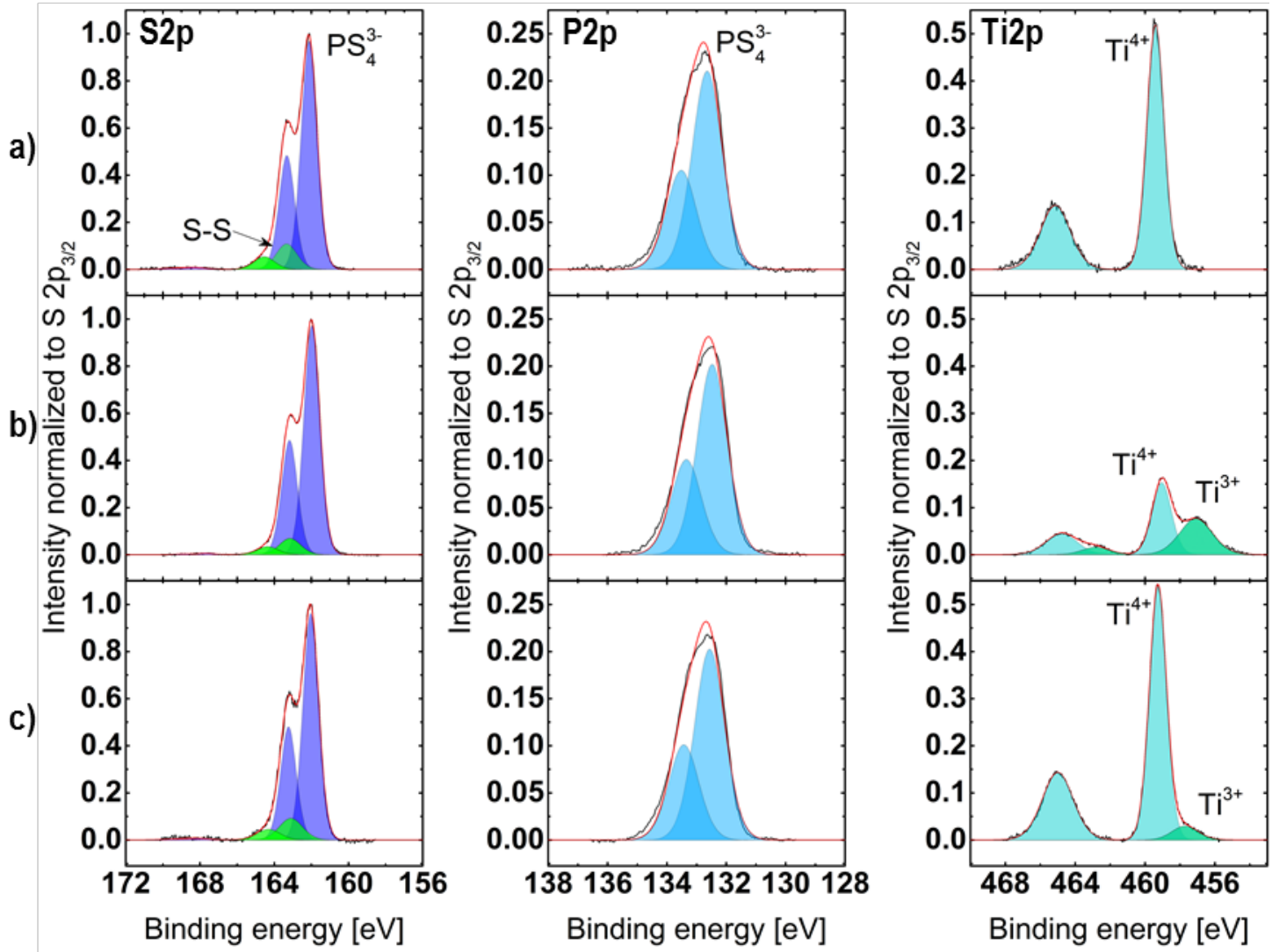

4 Figure 10. $S 2 p_{3 / 2-1 / 2}, P 2 p_{3 / 2-1 / 2}$, and Ti2 $p_{3 / 2-1 / 2}$ XPS core levels acquired on a LTO-composite cathode: a) pristine, b) fully 5 lithiated, and c) fully delithiated electrodes.

6 The reactivity of $\mathrm{Li}_{3} \mathrm{PS}_{4}$ with the InLix alloy counter electrode was also examined by XPS. Again, the 7 assumed formation of $\mathrm{Li}_{2} \mathrm{~S}\left(\mathrm{~S}_{2} \mathrm{p}_{3 / 2}\right.$ at $\left.160.7 \mathrm{eV}\right)$ was seen in the $\mathrm{S} 2 \mathrm{p}$ spectrum, along with the formation 8 of polysulfide species. Additionally, the reduction of phosphorous is suggested by the peak component 9 at $130.4 \mathrm{eV}$, attributed to InP.[20] Furthermore, a small amount of phosphate was observed. Besides the indication of metallic indium at $443.8 \mathrm{eV}\left(\ln 3 \mathrm{~d}_{5 / 2}\right), \ln \mathrm{P}$ is also indicated by a peak at $444.9 \mathrm{eV}$.[24]
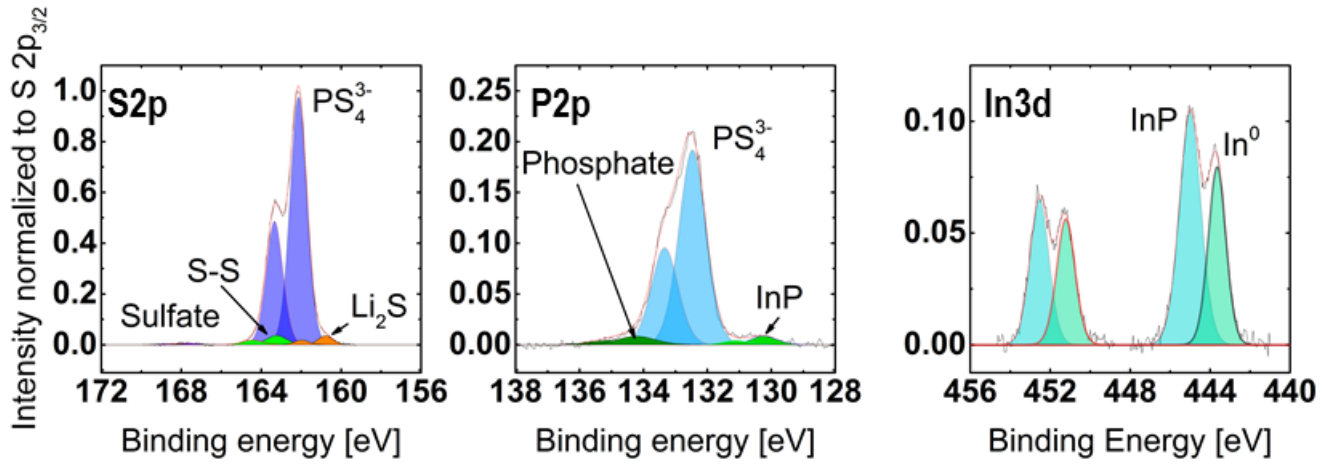

Figure 11. $S 2 p_{3 / 2-1 / 2}, P 2 p_{3 / 2-1 / 2}$, and $\ln 3 d_{5 / 2-3 / 2}$ XPS core level spectra acquired at the interface between $L_{3} P_{4}$ and the InLi alloy counter electrode.

The lithium stripping and plating behavior of the $\operatorname{InLi} \mathrm{i}_{x}$ counter electrode coupled with the $\mathrm{Li}_{3} \mathrm{PS}_{4}$ solid electrolyte were also studied. The peak values of the plating/stripping overpotential recorded for each 
cycle are shown in Figure 12. Sixty cycles were achieved without any noticeable internal short-circuiting. According to Equation 2, this value corresponds to $86 \%$ cyclic efficiency. However, the experiment was terminated due to the significant build-up in overpotential during lithium stripping. The increasing overpotential is indicative of the consumption of lithium at the counter electrode, which may be due to the formation of $\mathrm{Li}_{2} \mathrm{~S}$, as indicated by the XPS measurements.

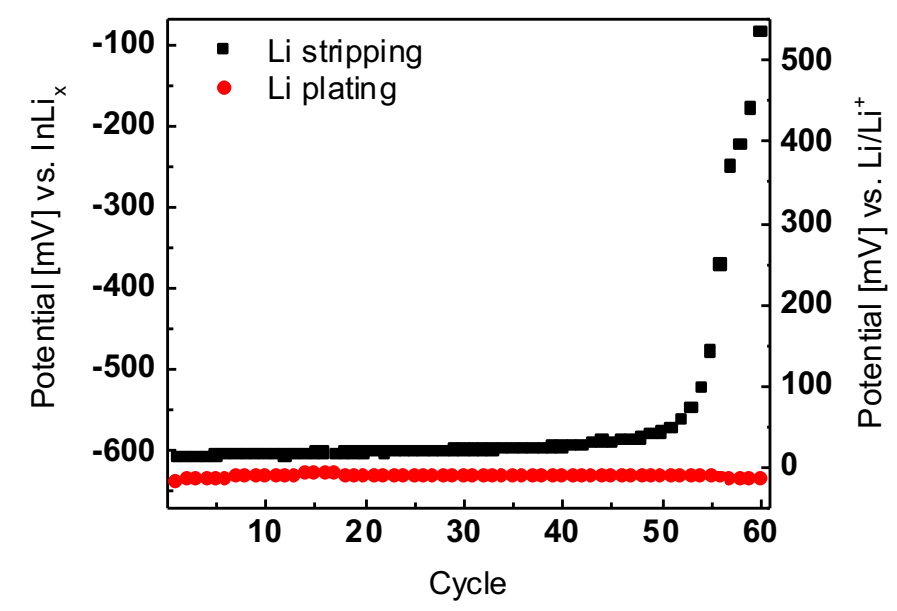

6

Figure 12. Maximal overpotential during lithium plating and stripping in an $\operatorname{InLi_{x}}\left|\mathrm{Li}_{3} \mathrm{PS}_{4}\right| \mathrm{SS}$ cell configuration.

\section{Conclusion}

An amorphous solid electrolyte with the nominal composition $\mathrm{Li}_{3} \mathrm{PS}_{4}$ was synthesized by ball milling. After obtaining a dense pellet with acceptable ionic conductivity, all-solid-state half-cells using LTO as the active material and an $I n L i_{x}$ counter electrode were tested. The replacement of metallic lithium by the InLi $\mathrm{i}_{x}$ alloy was determined to be the critical parameter for reversible cycling. The test cell exhibits good capacity retention at rates between $\mathrm{C} / 20$ to $\mathrm{C} / 5$ and long-term cyclic stability. Post-mortem XPS analysis was used to investigate the reactivity of $\mathrm{Li}_{3} \mathrm{PS}_{4}$ with $\mathrm{LTO}$, metallic lithium, and an InLix alloy. The reduction of $\mathrm{Li}_{3} \mathrm{PS}_{4}$ by the counter electrode was observed for both $\mathrm{Li}$ and $\ln \mathrm{Li}_{\mathrm{x}}$, resulting in the formation of $\mathrm{Li}_{2} \mathrm{~S}$. The rapid failure of the cell using a Li metal counter electrode can be explained by the formation of an internal short-circuit due to dendrite growth. No reduction of the solid electrolyte by LTO at $1.55 \mathrm{~V}$ vs. Li+/Li was observed. The electrode-electrolyte interface for $\mathrm{LTO}^{+}$and $\mathrm{Li}_{3} \mathrm{PS}_{4}$ is considered to be stable, and the electrochemical activity of LTO can be traced by XPS via the changes in the titanium oxidation state.

\section{Acknowledgement}

This work is supported by the Competence Center Energy and Mobility (CCEM) and the Swiss Electric research initiative (SER). We would like to thank Mr. Giulio Ferraresi for his help in the electrochemical tests and synthesis.

\section{References}

[1] C. Arbizzani, G. Gabrielli, M. Mastragostino, Journal of Power Sources, 196 (2011) 4801-4805. 

Energy, 1 (2016) 16030.

[3] N. Kamaya, K. Homma, Y. Yamakawa, M. Hirayama, R. Kanno, M. Yonemura, T. Kamiyama, Y. Kato, S. Hama, K. Kawamoto, A. Mitsui, Nat Mater, 10 (2011) 682-686.

[4] A. Hayashi, S. Hama, H. Morimoto, M. Tatsumisago, T. Minami, Journal of the American Ceramic Society, 84 (2001) 477-479.

[5] Y. Zhu, X. He, Y. Mo, ACS Appl Mater Interfaces, 7 (2015) 23685-23693.

[6] A. Sakuda, A. Hayashi, M. Tatsumisago, Chemistry of Materials, 22 (2010) 949-956.

[7] N. Ohta, K. Takada, L. Zhang, R. Ma, M. Osada, T. Sasaki, Advanced Materials, 18 (2006) 22262229.

[8] M. Nagao, A. Hayashi, M. Tatsumisago, Electrochemistry Communications, 22 (2012) 177-180.

[9] M. Nagao, A. Hayashi, M. Tatsumisago, T. Kanetsuku, T. Tsuda, S. Kuwabata, Phys Chem Chem Phys, 15 (2013) 18600-18606.

[10] S. Wenzel, S. Randau, T. Leichtweiß, D.A. Weber, J. Sann, W.G. Zeier, J. Janek, Chemistry of Materials, 28 (2016) 2400-2407.

[11] S. Wenzel, D.A. Weber, T. Leichtweiss, M.R. Busche, J. Sann, J. Janek, Solid State Ionics, 286 (2016) 24-33.

[12] F. Han, T. Gao, Y. Zhu, K.J. Gaskell, C. Wang, Advanced Materials, 27 (2015) 3473-3483.

[13] A. Sakuda, A. Hayashi, M. Tatsumisago, Sci Rep, 3 (2013) 2261.

[14] T. Yamada, S. Ito, R. Omoda, T. Watanabe, Y. Aihara, M. Agostini, U. Ulissi, J. Hassoun, B. Scrosati, J. Electrochem. Soc., 162 (2015) A646-A651.

[15] L. Boulet-Roblin, M. El Kazzi, P. Novák, C. Villevieille, Journal of The Electrochemical Society, 162 (2015) A1297-A1300.

[16] K. Takada, N. Aotani, K. Iwamoto, S. Kondo, Solid State Ionics, 86 (1996) 877-882.

[17] G. Appetecchi, F. Croce, G. Dautzenberg, M. Mastragostino, F. Ronci, B. Scrosati, F. Soavi, A. Zanelli, F. Alessandrini, P. Prosini, Journal of the Electrochemical Society, 145 (1998) 4126-4132.

[18] M. Tachez, J.-P. Malugani, R. Mercier, G. Robert, Solid State Ionics, 14 (1984) 181-185.

[19] F. Mizuno, A. Hayashi, K. Tadanaga, M. Tatsumisago, Solid State lonics, 177 (2006) 2721-2725.

[20] A.K.-V. Alexander V. Naumkin, Stephen W. Gaarenstroom, and Cedric J. Powell, in: Version 4.1, 2012.

[21] M. Fantauzzi, B. Elsener, D. Atzei, A. Rigoldi, A. Rossi, RSC Advances, 5 (2015) 75953-75963.

[22] Y. Son, J.-S. Lee, Y. Son, J.-H. Jang, J. Cho, Advanced Energy Materials, 5 (2015) n/a-n/a.

[23] M. Nagao, A. Hayashi, M. Tatsumisago, Electrochemistry, 80 (2012) 734-736.

[24] H. Virieux, M. Le Troedec, A. Cros-Gagneux, W.-S. Ojo, F. Delpech, C. Nayral, H. Martinez, B. Chaudret, Journal of the American Chemical Society, 134 (2012) 19701-19708. 